\title{
Optimizing the injection pressure for cluster nozzle concepts in a direct injection diesel engine
}

\author{
H W Won* and N Peters \\ Institut für Technische Verbrennung, Aachen, Germany \\ The manuscript was accepted after revision for publication on 19 November 2009.
}

DOI: 10.1243/14680874JER05409

\begin{abstract}
A combination of high-pressure injection and small orifices will be one of the strategies to achieve lean combustion. However, equispaced small orifices tend to increase soot under high-load condition because the spray tip penetration becomes exceedingly inadequate. For this reason, the cluster concept was chosen as a means to realize lean combustion. Six clusters were investigated with different injection pressures under part-load condition and high-load condition in a single-cylinder diesel engine, and the results were compared with a reference nozzle. The clusters tend to produce higher smoke than the reference nozzle for low injection pressures under conventional injection timing because the spray from the clusters with a shorter spray tip penetration loses momentum near the piston bowl. However, the clusters show improved smoke emissions with higher injection pressures. The combination of high-pressure injection and cluster concepts can be seen as one of the solutions to achieve lean combustion for diesel engines. Clusters with high-pressure injection have improved emissions, as better fuel atomization and evaporation are achieved while holding momentum near the piston bowl and maintaining the penetration of the spray.
\end{abstract}

Keywords: cluster nozzle, injection pressure, particulate emissions, common-rail diesel engine

\section{INTRODUCTION}

Nozzles with more and smaller orifices have contributed significantly to the improvement of diesel engines. A reduction in ignition delay and soot emissions has been observed for a higher number of smaller-diameter orifices. In view of the fact that no benefits are observed by increasing the number of holes in a nozzle above an optimum, and demands for better atomization and mixing require a further reduction in orifice diameter, the cluster concept was developed. The aim of the cluster nozzle concept is to keep the spatial distribution of the spray as close to a conventional nozzle as possible, in spite of the reduction in nozzle orifice diameter. However, nozzles with a smaller orifice and the cluster nozzle with a large positive included angle

${ }^{*}$ Corresponding author: Institut für Technische Verbrennung, Büro, Raum 210, 2. Etage, Templergraben 64, D - 52056 Aachen, Germany.

email: h.won@itv.rwth-aachen.de between the orifices tend to reduce spray tip penetration length while improving the atomization. Spray tip penetration for cluster nozzles with smaller included angles is larger than for clusters with large included angles but is smaller than for a conventional nozzle having the same flow number. A combination of high-pressure injection and cluster nozzles with small orifices could be one of the alternative hardware configurations to achieve lean combustion for the direct injection (DI) diesel engine. In the last few decades, numerous research efforts have been devoted to investigating the effects of increasing injection pressure and reducing hole size on diesel combustion and emission.

Nakakita et al. [1] studied the influence of injection pressure and timing on $\mathrm{NO}_{x}$ and soot. The experiment was conducted at 60 per cent relative speed ratio and 20-100 per cent load range. As a result, the formation of soot was reduced significantly, with higher injection pressure excluding the full-load condition where the reduction was small. 
Yokota et al. [2] investigated the relationship between the characteristics of non-evaporating sprays and their corresponding flames in a rapid compression machine. After comparing the Sauter mean diameter (SMD) and mean excess air ratio for sprays with different injection pressures, durations, and orifice diameters, they concluded that the main factor controlling the burning rate is the excess air ratio, and combustion duration and soot formation are reduced as the injection pressure is increased.

$\mathrm{Su}$ et al. [3] examined the character of high injection pressure, up to 1500 bar with 0.243 and $0.259 \mathrm{~mm}$ hole diameter injectors, using a singlecylinder engine and spray tests. Higher injection pressure produces lower soot, higher $\mathrm{NO}_{x}$, and lower particulate matter (PM) because of a smaller average droplet size according to SMD measurement. With $\mathrm{NO}_{x}$ kept at the same level, soot formation is significantly reduced by using smaller-hole nozzles.

Varde and Watanabe [4] performed tests using a common-rail injection system with an intensifier producing a pressure of up to $1600 \mathrm{bar}$. They found that the SMD at the outer region of the spray decreased with increased injection pressure. Peak and average pressure during injection were found to affect the formation of soot and $\mathrm{NO}_{x}$. Smoke, $\mathrm{NO}_{x}$, and fuel consumption rate were improved with variable dynamic injection timing and high injection pressure.

Higher-pressure injection produces faster sprays, increasing spray penetration and reducing the SMD. As the spray reaches the piston walls, the vapour spreads over a larger surface area and moves further along the wall towards the bottom of the bowl and radially inwards to the centre of the bowl. This improves the mixing of the fuel with the bulk of the air in the bowl. In addition, higher injection pressures enhance the development of faster wall jets producing more turbulence and better mixing. These three factors increase the premixed combustion fraction. The reduction in soot emissions at the higher injection pressures is mainly due to the improved homogeneity of the charge. Another factor that might have contributed to the drop in soot emission is the reduction in the fraction of the fuel injected in the flame [5-9].

Dec [10] suggests that a premixed standing flame located downstream of the liquid tip is a major source of soot precursors during the mixing-controlled combustion phase. Siebers and Higgins [11] found that doubling the injection velocity increases the lift-off such that more air is entrained into the spray before the fuel reaches the combustion zones. This has the potential to decrease soot precursor formation in the premixed flame zone [12].
In a previous study at RWTH, three clusters were designed with seven hole-pairs (cluster $14 \times 150 / 130$, cluster $14 \times 160 / 120$, and cluster $14 \times 140 / 140$ ). The naming of the clusters, which is the same as in the present study, is explained in section 2. The clusters were investigated in a high-pressure combustion vessel, using optical measurement techniques, and compared with a conventional nozzle with the same flow rate. They were also investigated in an engine under part-load condition for premixed charge compression ignition (PCCI) operation and under high load for conventional diesel operation. The engine results were compared with a conventional seven-hole nozzle for reference. The experiments in the combustion vessel showed lower soot concentrations for cluster nozzles in comparison with the reference nozzle. The engine experiments showed some improvement for $14 \times 160 / 120$ under PCCI operation, but the results for cluster nozzles were worse than for the reference nozzle for all other conditions. Analysis of results through numerical investigations showed that the effect of worse spray targeting due to smaller spray-cone angles (chosen for improved operation with early injection timings) outweighed the advantage of the cluster concept, resulting in higher smoke emissions [13-15]. Pawlowski et al. performed spray measurements for the nozzles and found the clusters to have smaller vapour and liquid penetration and axial droplet velocities than the reference nozzle [16].

Based on the above observations, a new set of clusters was designed for the present study. The new clusters include nozzles with five, six, and seven hole-pairs with two different geometric configurations for orifice placement. As the previous study had pointed out that spray targeting was extremely important for high-load operation, an attempt was made to keep the targeting as close to the conventional nozzle as possible for all the nozzles. Cardenas et al. have performed spray measurements for a similar set of clusters [17]. The clusters were investigated in a single-cylinder engine with different rail pressures for two different test points, and the results were compared with the reference nozzle. The test points were denoted as TP1 for low-load condition and TP2 for high-load condition.

\section{EXPERIMENTAL SET-UP}

\subsection{Experimental facility}

The experiments were performed on a $0.8 \mathrm{~L}$ singlecylinder engine (16.5:1 compression ratio) with a 1.5 swirl ratio, based on a V-8 Duramax engine from 
General Motors. The specifications of the singlecylinder engine are given in Table 1. The engine is equipped with a Bosch CRI-3.3 injection system for the cluster nozzles. A piezo injector was used to improve the combustion further. The more accurate control, faster response, and higher needle velocities of piezo injectors allow more precise control of injection duration. The injectors are controlled using a GENOTEC injection controller. A re-entrant combustion chamber of $59.8 \mathrm{~mm}$ throat diameter and $15.6 \mathrm{~mm}$ depth was used for the measurement. The scheme of the engine test cell is shown Fig. 1. In order to keep the intake air conditions identical to the real production engine, a three-step compressor supplied the required boost pressure, while air

Table 1 Specifications of the Duramax single-cylinder engine

\begin{tabular}{ll}
\hline Engine & $\begin{array}{l}\text { Duramax single- } \\
\text { cylinder engine }\end{array}$ \\
\hline Displacement volume (L/cylinder) & 0.825 \\
Bore (mm) & 103 \\
Stroke (mm) & 99 \\
Connecting rod length (mm) & 188 \\
Piston pin offset (mm) & 0.5 \\
Compression ratio & $16.5: 1$ \\
Squish height (mm) & 0.7 \\
Swirl ratio & 1.5 \\
Maximum rail pressure (bar) & 2200 \\
Maximum pressure in cylinder (bar) & 160 \\
Maximum speed (min ${ }^{-1}$ ) & 3600 \\
\hline
\end{tabular}

temperature at the engine intake was controlled by three intercoolers, maintaining the desired inlet conditions in the surge tank of the intake pipe. Airflow rate was measured by a hot-wire flow meter. The exhaust back-pressure produced by a throttle valve in the real engine was simulated by a valve placed in the exhaust system, controlling the pressure in the exhaust surge tank. An EGR valve allows control of exhaust gas recirculation (EGR) rate. Dedicated conditioners are used to maintain the temperature and pressure of the coolant and oil. The cylinder pressure was measured with a Kistler 6041A pressure transducer. The pressure traces for 50 engine cycles were averaged in order to compensate for statistical dispersion in engine operation.

The study was carried out in a test cell equipped with an $\mathrm{ABB}$ emissions bench for gaseous emission measurements. The $\mathrm{CO}_{2}$ (vol \%), $\mathrm{CO}$ (vol \%), $\mathrm{CO}$ (ppm), $\mathrm{O}_{2}$ (vol \%), $\mathrm{HC}$ (hydrocarbons) $\left(\mathrm{mg} / \mathrm{m}^{3}\right)$, and $\mathrm{NO}_{\mathrm{x}}(\mathrm{ppm})$ measurements were transformed into the emission index $(\mathrm{g} / \mathrm{kg}$ fuel). Particulate mass calculated for this work was based on the filter smoke number (FSN) to calculate a correlation factor from the equation

$$
\begin{aligned}
A= & 0.0307 \times \mathrm{FSN}^{5}-0.00669 \times \mathrm{FSN}^{4}-0.702 \times \mathrm{FSN}^{3} \\
& +14.621 \times \mathrm{FSN}^{2}+7.363 \times \mathrm{FSN}
\end{aligned}
$$

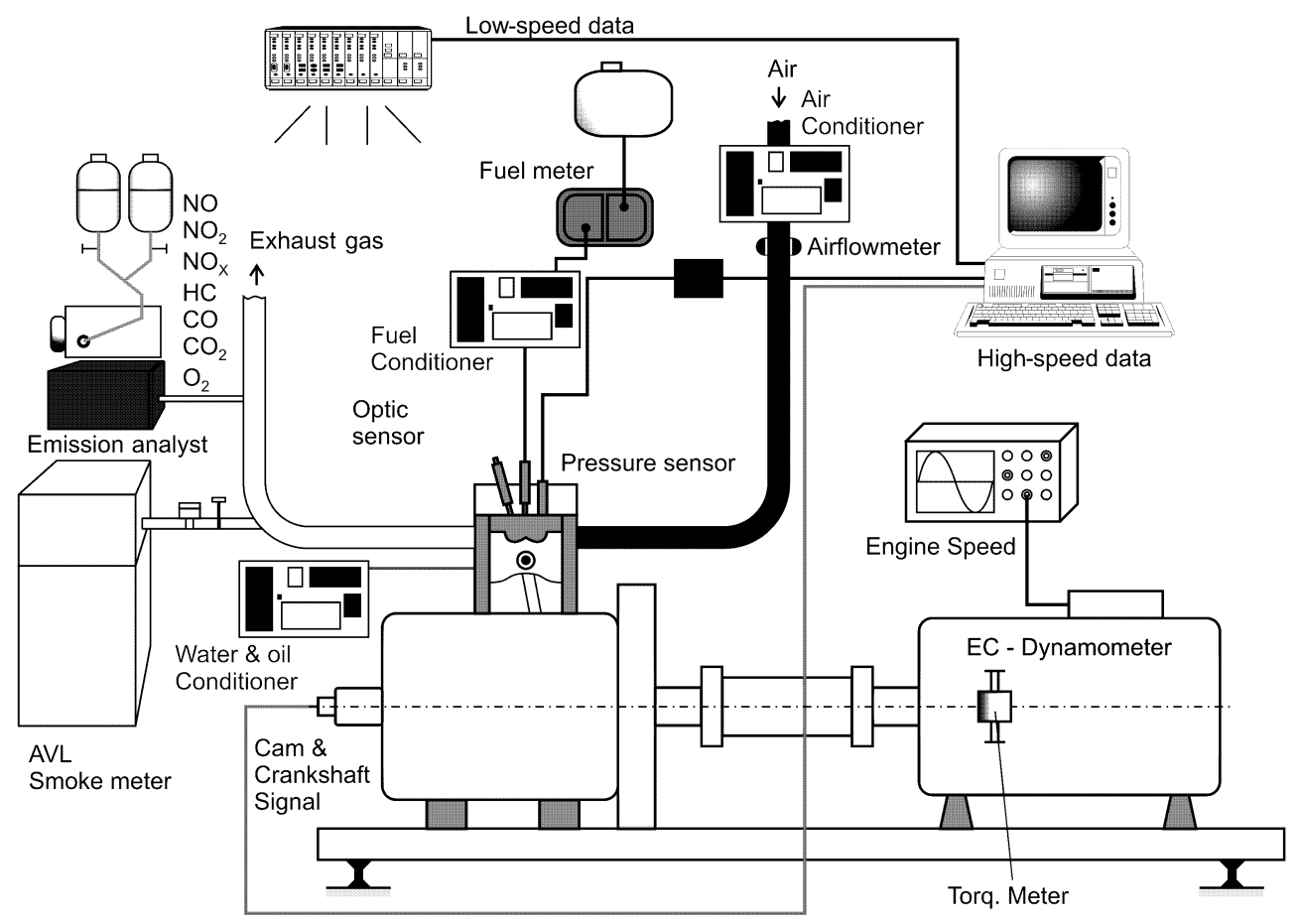

Fig. 1 Schematic diagram of the engine test cell 
The FSN numbers were read from an AVL Model 415 smoke meter, and the emission index of dry soot (in $\mathrm{g} / \mathrm{kg}$ fuel) was calculated using equation (2) for the 'MIRA' correlation [18] which was developed by a European research organization

$$
\text { MIRA dry soot mass }=A \times\left(\frac{\mathrm{AFR}=1}{1000}\right)
$$

where AFR is the air-fuel ratio.

Further valuable information was extracted from in-cylinder pressure, such as the heat release rate (HRR) and several related parameters, such as combustion duration, ignition delay, etc. This is based on the solution of the energy balance equation inside the cylinder, under assumptions of uniform pressure and temperature across the volume. This makes it possible to calculate the instantaneous average temperature as well as the instantaneous heat released from the burnt fuel.

\subsection{Cluster nozzles}

A total of six clusters with different numbers of holepairs, each having a $10^{\circ}$ included angle, were designed for the present study. All the clusters had groups of two orifices with the same hole diameter, as this leads to reasonable orifice sizes. Table 2 lists the parameters for the reference nozzle and the clusters. Two different orientations for placement of the orifices were used. The clusters with one orifice circle (henceforth referred to as 'horizontal') have both orifices placed in a plane perpendicular to the injector axis, forming only one spray cone, while the clusters with two orifice circles (henceforth referred to as 'vertical') have the two orifices of a group placed along the injector axis, effectively forming two spray cones. Figure 2 shows a sketch of the orifice orientation for the clusters. Three of the clusters have the vertical configuration and three have the horizontal configuration. The horizontal clusters were designed with the same spray-cone

Table 2 Geometric specifications of the cluster nozzles and the reference nozzle

\begin{tabular}{|c|c|c|c|c|c|c|c|}
\hline $\begin{array}{l}\text { Number of hole- } \\
\text { pairs (holes) }\end{array}$ & Centre-line angle $\beta$ & $\begin{array}{l}\text { Included } \\
\text { angle } \alpha\end{array}$ & $\begin{array}{l}\text { Orifice size } \\
(\mathrm{mm})\end{array}$ & $\begin{array}{l}\text { Hole } \\
\text { separation } \\
(\mathrm{mm})\end{array}$ & $\begin{array}{l}\text { Flow number } \\
\left(\mathrm{cm}^{3} / 30 \mathrm{~s} \text { at } 100 \mathrm{bar}\right)\end{array}$ & $\begin{array}{l}\text { Cluster } \\
\text { configuration }\end{array}$ & Name \\
\hline $7(7)$ & 158 & - & 0.135 & - & 405 & - & $7 \times 158$ \\
\hline 7 (14) & 158 & 10 & 0.105 & 0.500 & 490 & 02 & $14 \times 158 / 158$ \\
\hline $6(12)$ & 158 & 10 & 0.113 & 0.600 & 490 & 02 & $12 \times 158 / 158$ \\
\hline $5(10)$ & 158 & 10 & 0.123 & 0.600 & 490 & 02 & $10 \times 158 / 158$ \\
\hline 7 (14) & $148(158 / 138)$ & 10 & 0.105 & 0.600 & 490 & 01 & $14 \times 158 / 138$ \\
\hline $5(10)$ & $148(158 / 138)$ & 10 & 0.113 & 0.600 & 430 & 01 & $10 \times 158 / 138$ \\
\hline
\end{tabular}

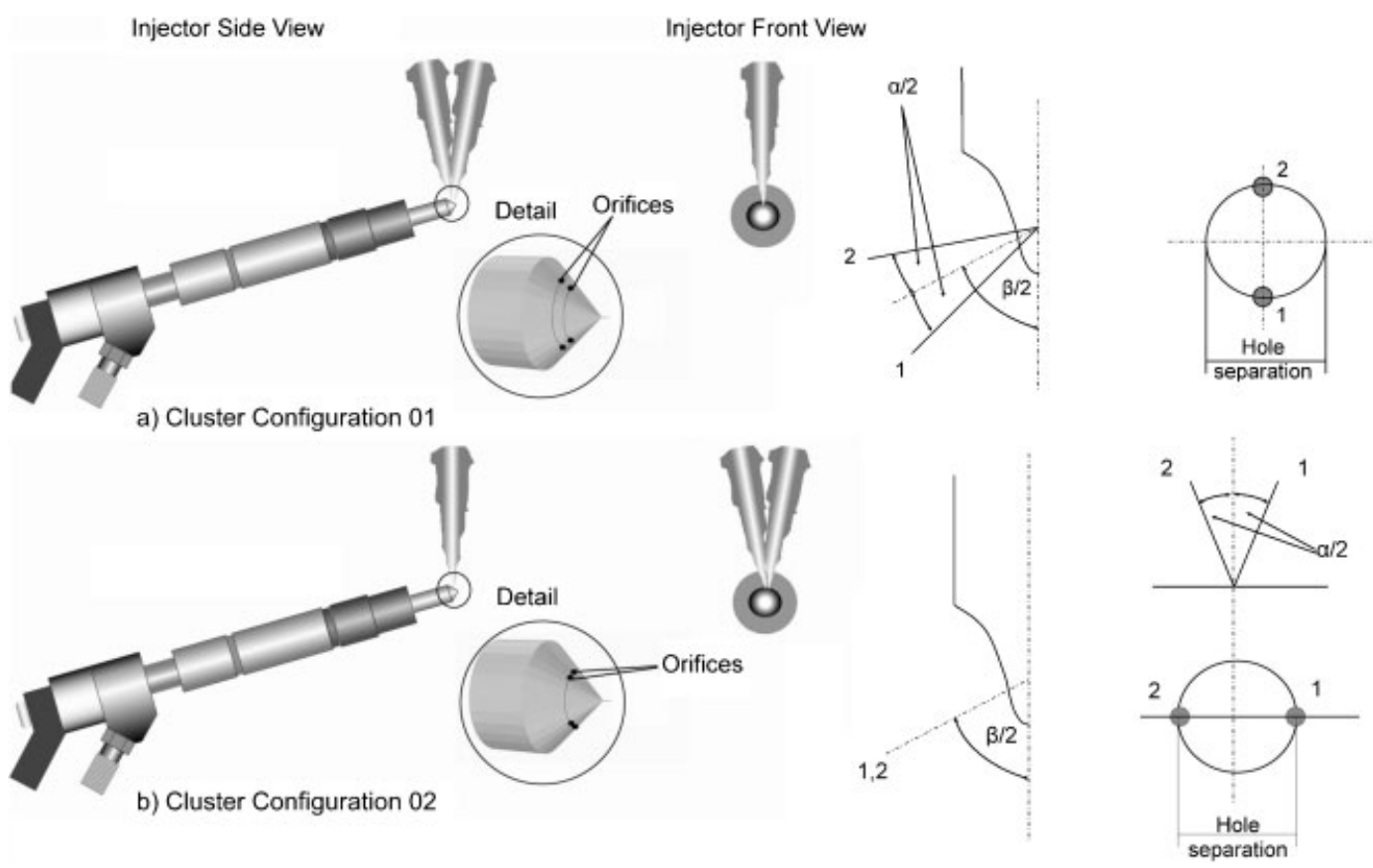

Fig. 2 Sketch of orifice orientation for the horizontal (top) and the vertical (bottom) clusters 
angle as the reference injector $\left(158^{\circ}\right)$ for better targeting, and the outer spray of vertical clusters also had a similar spray-cone angle to the reference injector $\left(158^{\circ}\right)$.

The clusters are named according to their geometry. The first part denotes the total number of orifices $(10,12$, or 14$)$. The two numbers separated by a slash denote the spray cone angle formed by the orifices in different orifice circles (only one orifice circle for the horizontal configuration). The reference nozzle has a flow number of 405, and was designed with a $0.131 \mathrm{~mm}$ orifice diameter. The clusters with seven hole-pairs were designed with a $0.093 \mathrm{~mm}$ orifice diameter for a flow number of 490 . The flow number is defined as the amount of fuel (in $\mathrm{cm}^{3}$ ) that flows through the nozzle in $30 \mathrm{~s}$ at a pressure difference of 100 bar. The seven hole-pair clusters were designed with a higher flow number to match the spray tip penetration to the reference nozzle. The other clusters with six and five hole-pairs were designed for the same flow number $\left(490 \mathrm{~cm}^{3} / 30 \mathrm{~s}\right.$ at $\left.100 \mathrm{bar}\right)$. The clusters were designed with different orifice diameters to keep the same flow number. However, cluster $10 \times 158 / 138$ has a slightly lower flow number than the other clusters.

\subsection{Test points}

The test points are described in Table 3 . Test point TP1 represents a low-load operation, while test point TP2 represents a high-load condition. The $\mathrm{NO}_{x}$ emission index and the indicated mean effective pressure (i.m.e.p.) were kept constant for all the tests within the corresponding test points, while the start of pulse (SOP) and rail pressure were varied within the limits shown. The delay between the SOP and actual injection was $3^{\circ}$ crank angle (CA) for all cases. First, the clusters and reference nozzle were separately tested for different pressures ranging from 500 to 900 bar under low load at an SOP of $-5^{\circ} \mathrm{CA}$ at top dead centre (TDC). Then they were investigated for SOP variation with two different rail pressures for each test point, namely 600 and 900 bar for TP1 and
1200 and 1500 bar for TP2. The SOP variation was carried out from $-30^{\circ}$ to $-3^{\circ} \mathrm{CA}$ at TDC in $3^{\circ}$ steps for TP1, and from $-10^{\circ}$ to $4^{\circ} \mathrm{CA}$ at TDC in $2^{\circ}$ steps for TP2. The injection duration was varied to maintain the i.m.e.p., while $\mathrm{NO}_{x}$ was maintained at constant levels for different sets of experiments by varying the EGR. Injection rate measurements were carried out for all the nozzles to determine the actual injected mass for the test points.

\section{RESULTS AND DISCUSSION}

\subsection{Pressure and heat release}

Ignition delay in the case of the cluster nozzles is generally shorter than in the case of the conventional nozzle. The initial rate of heat release is also higher for the cluster nozzles. The combustion period is shortened. With the higher heat release during the premixed phase, the clusters normally have a higher combustion temperature and correspondingly show an increase in $\mathrm{NO}_{x}$ emissions. Therefore, they require a higher EGR rate than the reference nozzle to keep the same of $\mathrm{NO}_{x}$ emission index. The clusters were designed with different orifice diameters to keep the same flow number; cluster $10 \times 158 / 138$ has a slightly lower flow number than the other clusters. The differences between the cluster nozzles with respect to their different configurations and different hole diameters are also apparent from the pressure and heat release curves shown below.

\subsubsection{Low-load condition (TP1)}

Figure 3 shows the pressures and heat releases of the horizontal clusters with five, six, and seven holepairs and the reference nozzle under TP1. Even though the clusters had a higher EGR rate to keep the same emission index of $\mathrm{NO}_{x}$, they showed a shorter ignition delay than the reference nozzle. The combustion periods of the clusters were also shorter than those of the reference nozzle. All the clusters except the five-hole-pair cluster show higher heat

Table 3 Engine operating conditions

\begin{tabular}{lll}
\hline Test point & TP1 & TP2 \\
\hline Engine speed (r/min) & 1400 & 1400 \\
Rail pressure (bar) & $500-900$ & 1200 and 1500 \\
i.m.e.p. (bar) & 4.5 & 10.5 \\
Start of pulse (deg CA at TDC) & -30 to -3 (step 3) & -10 to 4 (step 2) \\
Boost pressure (bar) & 1.13 & 1.57 \\
Boost temperature $\left({ }^{\circ} \mathrm{C}\right)$ & 55 & 57 \\
Temperature of oil and coolant $\left({ }^{\circ} \mathrm{C}\right)$ & 90 & 90 \\
NO $_{x}$ emission index $(\mathrm{EGR})(\mathrm{g} / \mathrm{kg}$ fuel) & 4 & 4.5 \\
\hline
\end{tabular}




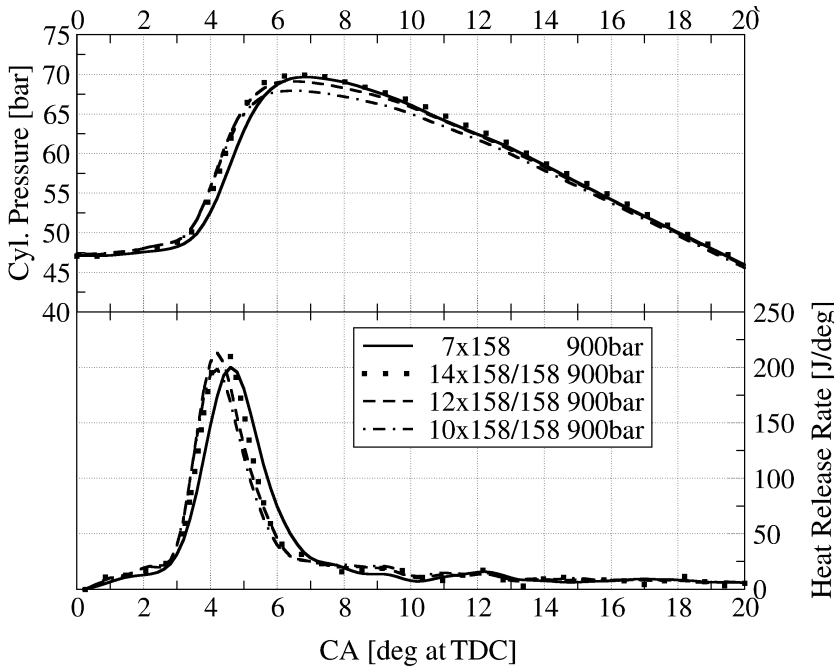

Fig. 3 Pressure and heat release for the horizontal clusters under TP1: $-6^{\circ} \mathrm{CA}$ at TDC SOP, $4.5 \mathrm{bar}$ i.m.e.p.

release rates than the reference nozzle. The clusters with high-pressure injection have better atomization and evaporation. Among the clusters, the sevenhole-pair cluster has the highest heat release rate, and the five-hole-pair cluster shows the lowest heat release rate. The vertical clusters with five, six, and seven hole-pairs and the reference nozzles are compared in Fig. 4 . The trends of pressure and heat release rate were similar to the trends for the horizontal clusters.

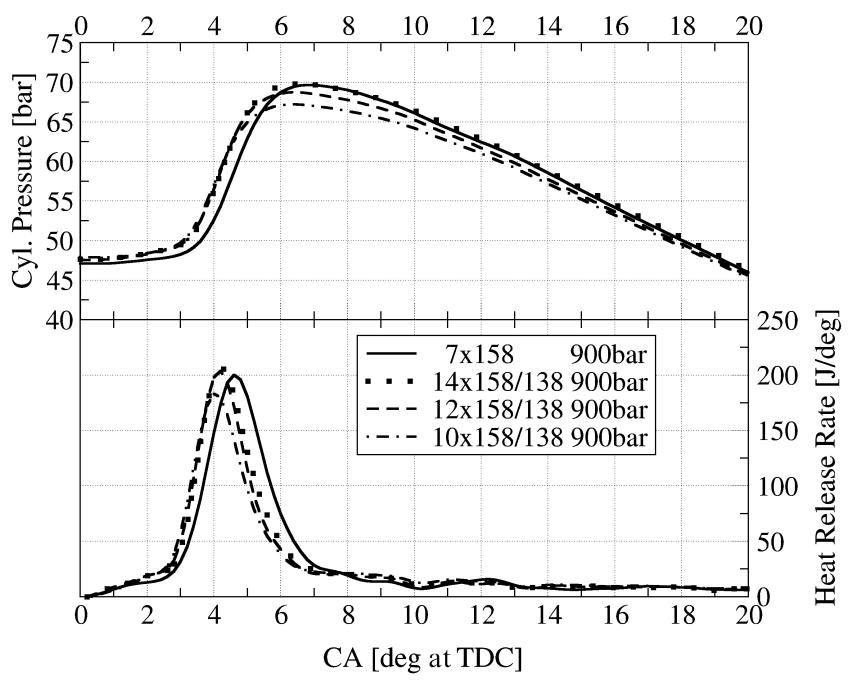

Fig. 4 Pressure and heat release for the vertical clusters under TP1: $-6^{\circ} \mathrm{CA}$ at TDC SOP, 4.5 bar i.m.e.p.

\subsubsection{High-load condition (TP2)}

Figure 5 shows the pressure and heat release rates for the horizontal clusters with five, six, and seven hole-pairs and the reference nozzle under TP2. The clusters have ignition delays similar to the reference nozzle, but the heat release rates of the clusters with better evaporation are higher than those of the reference nozzle during premixed combustion. A lower rate of heat release for the clusters than for the reference nozzle during the mixing-controlled combustion phase indicates that a large number of the droplets were already consumed during the premixed combustion phase for the clusters. The fivehole-pair cluster has the lowest heat release rate. The vertical clusters and the reference nozzle are compared in Fig. 6. The trends of pressure and heat release rates are similar to the results for the horizontal clusters, the heat release rates for clusters being higher during the premixed combustion and lower during the mixing-controlled combustion.

\subsubsection{Variation in rail pressure}

Figure 7 shows the pressure traces, heat release rates, and cumulative heat release curves for cluster $14 \times 158 / 158$ and the reference nozzle with 600 and 900 bar rail pressure. The cluster shows short ignition delay and combustion duration similar to previous figures. The ignition delays and the combustion duration of both nozzles were reduced by high injection pressure. The peak pressure and maximum heat release rate were increased by higher injection pressure.

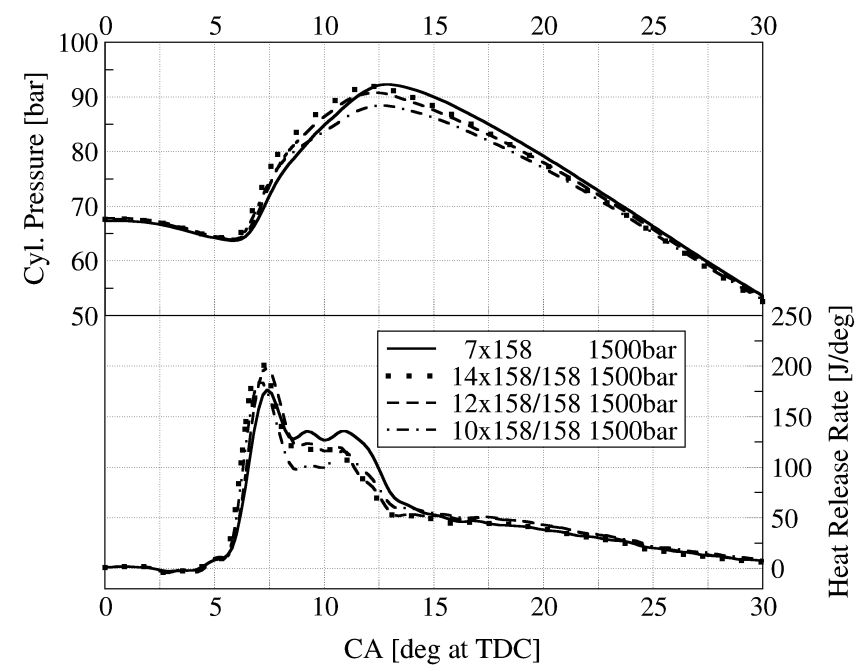

Fig. 5 Pressure and heat release for the horizontal clusters under TP2: $0^{\circ}$ CA at TDC SOP, 10.5 bar i.m.e.p. 


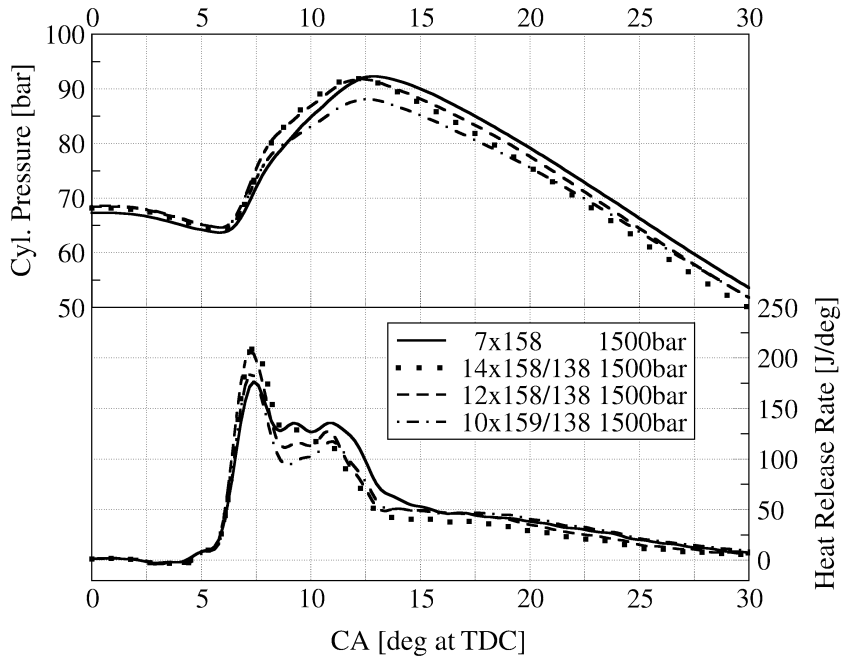

Fig. 6 Pressure and heat release for the vertical clusters under TP2: $0^{\circ} \mathrm{CA}$ at TDC SOP, 10.5 bar i.m.e.p.

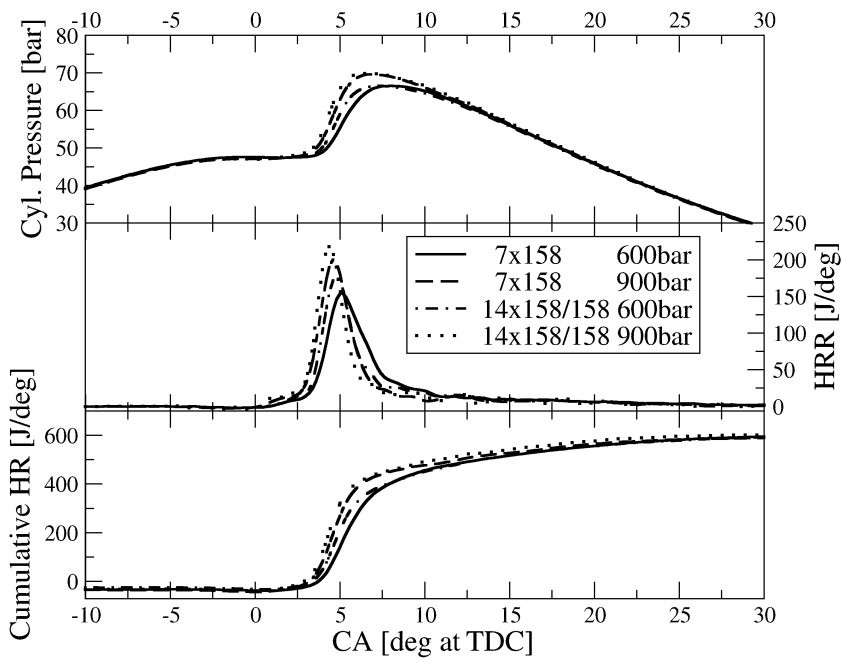

Fig. 7 Pressure and heat release curves for cluster $14 \times 158 / 158$ and the reference nozzle under TP1: 600 and 900 bar rail pressure, $-6^{\circ} \mathrm{CA}$ at TDC SOP, 4.5 bar i.m.e.p.

The cluster was also compared with the reference nozzle under TP2 (Fig. 8). The cluster with higher injection pressure has the earliest ignition in this case. The ignition delay was reduced with higher injection pressure or using a smaller-orifice nozzle. With higher injection pressure, the premixed combustion duration, as well as the rate of heat release during that period, is increased, while the mixingcontrolled combustion duration is shortened with high injection pressure. The overall combustion duration is reduced with higher injection pressure. It is notable that in this case the ignition delay, as well as the initial rate of heat release, is almost

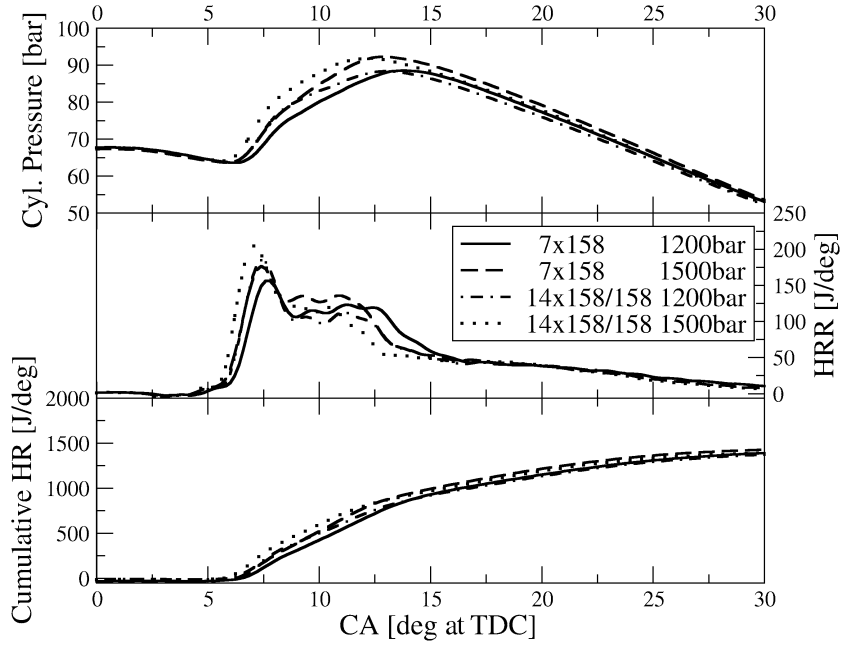

Fig. 8 Pressure and heat release curves for cluster $14 \times 158 / 158$ and the reference nozzle under TP2: 1200 and 1500 bar rail pressure, $0^{\circ} \mathrm{CA}$ at TDC SOP, 10.5 bar i.m.e.p.

identical for the conventional nozzle with 1500 bar and the cluster nozzle with 1200 bar.

\subsection{Emissions}

\subsubsection{Rail pressure variation}

Figure 9 shows smoke emissions for different rail pressures at an SOP of $-5^{\circ} \mathrm{CA}$ at TDC. The clusters show extremely high smoke for lower rail pressure under conventional injection timing for TP1. Among the compared clusters, the seven-hole-pair clusters with relatively smaller orifices show lower smoke than the other clusters, but it is still higher than that of the reference nozzle. As the atomization characteristics of the seven-hole-pair clusters are better than those of the reference nozzle, this behaviour can only be explained by the shorter spray tip penetration. It is evident that the use of a smallorifice nozzle is not sufficient to reduce the smoke levels for the clusters down to the level for the reference nozzle. It is also necessary to increase the rail pressure for this purpose. The smoke emissions of the clusters were reduced down to a smoke level similar to that of the reference nozzle by increasing the rail pressure. The reduction in smoke emissions at higher injection pressures is mainly due to the improved homogeneity of the charge. Another factor that might have contributed to the drop in smoke emission is reduction in the fraction of fuel injected into the flame. As noted above, the injection velocity increases the lift-off, which allows more air to be entrained into the spray before the fuel reaches the combustion zones. 


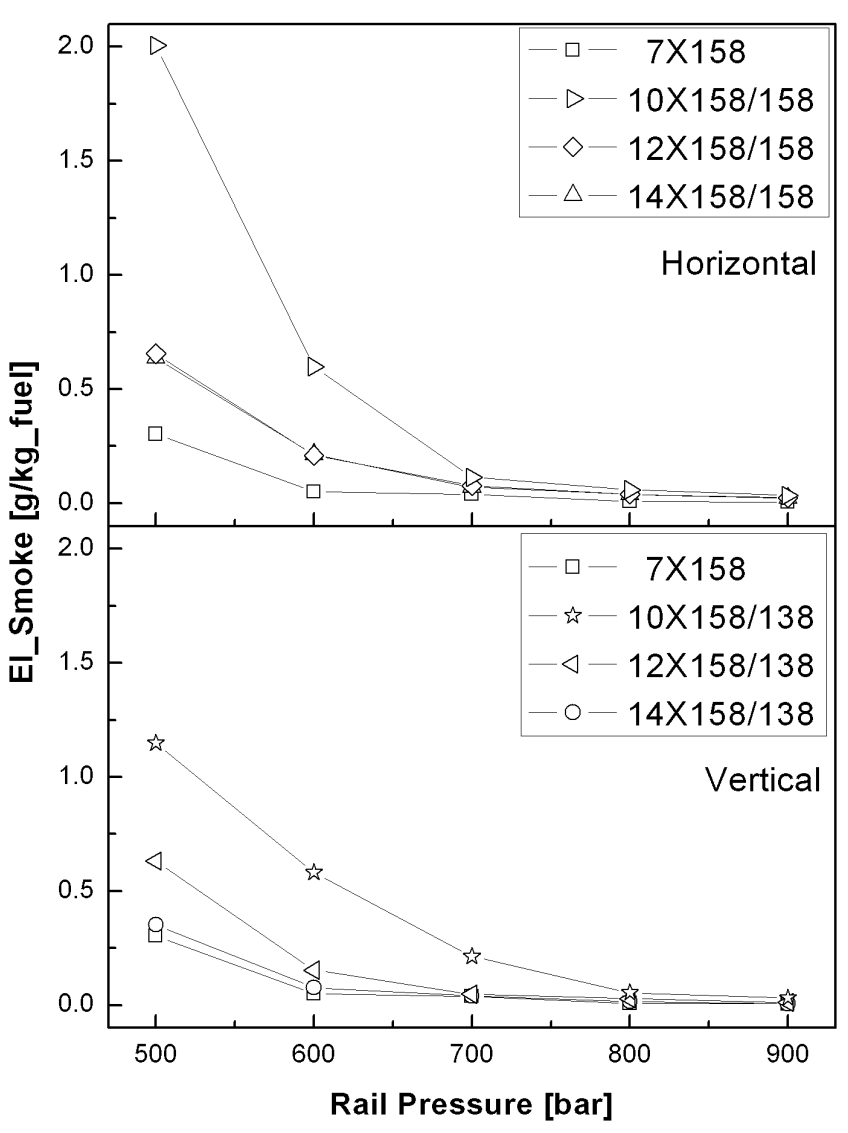

Fig. 9 Smoke with different rail pressures for TP1: $1400 \mathrm{r} / \mathrm{min}, 4.5$ bar i.m.e.p., $4 \mathrm{~g} / \mathrm{kg}$ fuel of $\mathrm{NO}_{x}$ at SOP $-5^{\circ} \mathrm{CA}$ at TDC

\subsubsection{Premixed charge compression ignition (PCCI)}

In PCCI, fuel is injected very early to produce a premixed fuel-air charge before ignition. It requires a large amount of cooled EGR to delay the ignition timing, which lowers the combustion temperature. The results are discussed for an early injection timing of $-27^{\circ} \mathrm{CA}$ at TDC SOP with a 600 bar rail pressure for different EGR rates under TP1. The results for fuel consumption, $\mathrm{HC}$, and smoke are shown in Fig. 10.

The brake specific fuel consumptions (b.s.f.c.) of the clusters are lower than for the reference nozzle. Clusters having small orifices are regarded as a promising approach to lowering fuel consumption at the early injection timing, because the sprays from clusters have a greater mass of entrained ambient gas and more mass of fuel vapour compared with the reference nozzle. In PCCI condition, hydrocarbon (HC) and carbon monoxide (CO) emissions are of major concern, because HC and CO emissions are usually higher when the combustion temperature is low. The cluster shows an improvement for $\mathrm{HC}$, because the reference nozzle with long spray tip

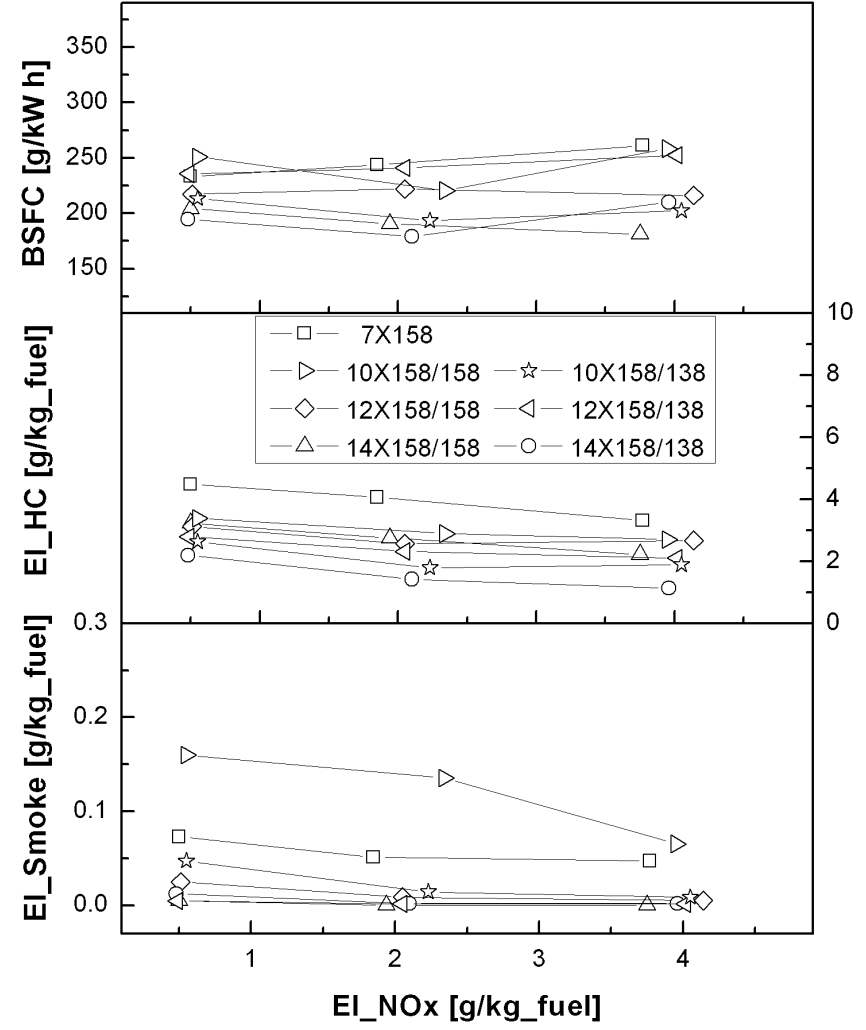

Fig. 10 Brake specific fuel consumption (b.s.f.c.), HC, and smoke for TP1: $1400 \mathrm{r} / \mathrm{min}, 600$ bar rail pressure, 4.5 bar i.m.e.p. at SOP $-27^{\circ} \mathrm{CA}$ at TDC

penetration causes more fuel to be delivered in proximity to the cylinder liner and combustion chamber walls, where flame quenching occurs. The size of the orifice is an important parameter for smoke emission in lean mixture conditions such as in PCCI. Lower soot emissions for the lower oxygen concentration conditions, which have substantially lower flame temperatures, suggest that $\mathrm{NO}_{x}$ and soot can potentially be simultaneously reduced with small orifices and EGR. The clusters, except cluster $10 \times 158 / 158$, show lower smoke than the reference nozzle. The clusters were designed with different orifice diameters to keep the same flow number, except cluster $10 \times 158 / 138$ which had a smaller flow number compared with the others. Among the two five-hole-pair clusters, cluster $10 \times 158 / 138$ showed lower smoke than the reference nozzle, as it had the smaller orifice diameter of the two owing to its smaller flow number. The other five-hole-pair cluster $10 \times 158 / 158$ showed considerably higher smoke. The orifice diameter for the individual orifices of cluster $10 \times 158 / 158(0.123 \mathrm{~mm})$ is slightly smaller than that of the reference nozzle $(0.135 \mathrm{~mm})$. However, the interaction between the two jets of a hole-pair suppresses ambient gas entrainment and 
evaporation compared with a single orifice of the size same as one orifice of the pair [19], making the spray characteristics of a hole-pair similar to those of a larger orifice. Moreover, a smaller number of orifice groups worsens the fuel distribution in the combustion chamber and thus increases soot. The size of the orifice is a very important parameter for smoke emission in lean mixture conditions such as in PCCI. Better performance of the five-hole-pair cluster with smaller orifices hints that, for a fivehole-pair nozzle with the same flow number, the orifices are not small enough to be beneficial over slightly larger single orifices of seven-hole conventional nozzles. The b.s.f.c., HC, and smoke levels stay more or less the same with different $\mathrm{NO}_{x}$ levels. It seems that a change in $\mathrm{NO}_{x}$, which is achieved by a change in EGR, has no effect on b.s.f.c., HC, and smoke, which is different from the situation with conventional injection timings. There are two strong effects with high EGR for early injection strategy. The first effect is dilution of oxygen with high EGR, which has a negative effect on b.s.f.c., HC, and smoke emissions, and the second effect is a longer ignition delay with higher EGR (ignition closer to TDC), which has a positive effect for them. Because of these effects, the trade-offs of b.s.f.c., HC, and smoke with $\mathrm{NO}_{x}$ were reduced for early injection timings under part load.

\subsubsection{Low-load condition (TP1)}

The clusters were used to investigate the effects of rail pressure for different SOP under low-load condition, and the results were compared with the reference nozzle. The size of the orifice and spray tip penetration should be an important parameter for TP1, because a small mass of fuel was injected into the chamber with low temperature and low pressure. Here, the clusters with smaller orifices should have an advantage with long ignition delay at early injection timing, but they tend to reduce spray tip penetration and the spray makes a rich zone. High injection pressures are required for the clusters to improve smoke emissions through increase in premixed combustion fraction. An increase in injection pressure with a small injected quantity brings negative results for HC and b.s.f.c. under TP1. The smoke forms in the rich unburned-fuel-containing core of the fuel sprays, within the flame region, where the fuel vapour is heated by mixing with hot burned gases. When a small quantity of fuel is injected with high injection pressure into a chamber of low temperature and low pressure, the smoke is lowered by the reduced rich zones in the fuel jet. However, the dilution has a negative impact on heat release, which causes a higher b.s.f.c. Hydrocarbons originate in regions where the flame quenches either close to the walls or where excessive dilution with air prevents the combustion process. In this case, excessive dilution of the spray is the more probable cause of higher HC emissions.

The results of b.s.f.c. using five-, six-, and sevenhole-pair clusters are shown for variation in SOP in Fig. 11. The clusters have better fuel consumption than the reference nozzle for all injection timings. The b.s.f.c. with 900 bar rail pressure is generally higher than with 600 bar rail pressure. These are effects from the dilution of spray and increase in unburned $\mathrm{HC}$ emissions.

In low-load condition, $\mathrm{HC}$ emissions are also of major concern, because HC emissions are usually higher when the combustion temperature is low. The HC emissions of five-, six-, and seven-hole-pair clusters are measured for a variation in SOP under TP1, and the results are compared with the reference nozzle in Fig. 12. The HC emissions of all the nozzles were higher at early and late injection timings. At early injection timings, more fuel reaches the piston

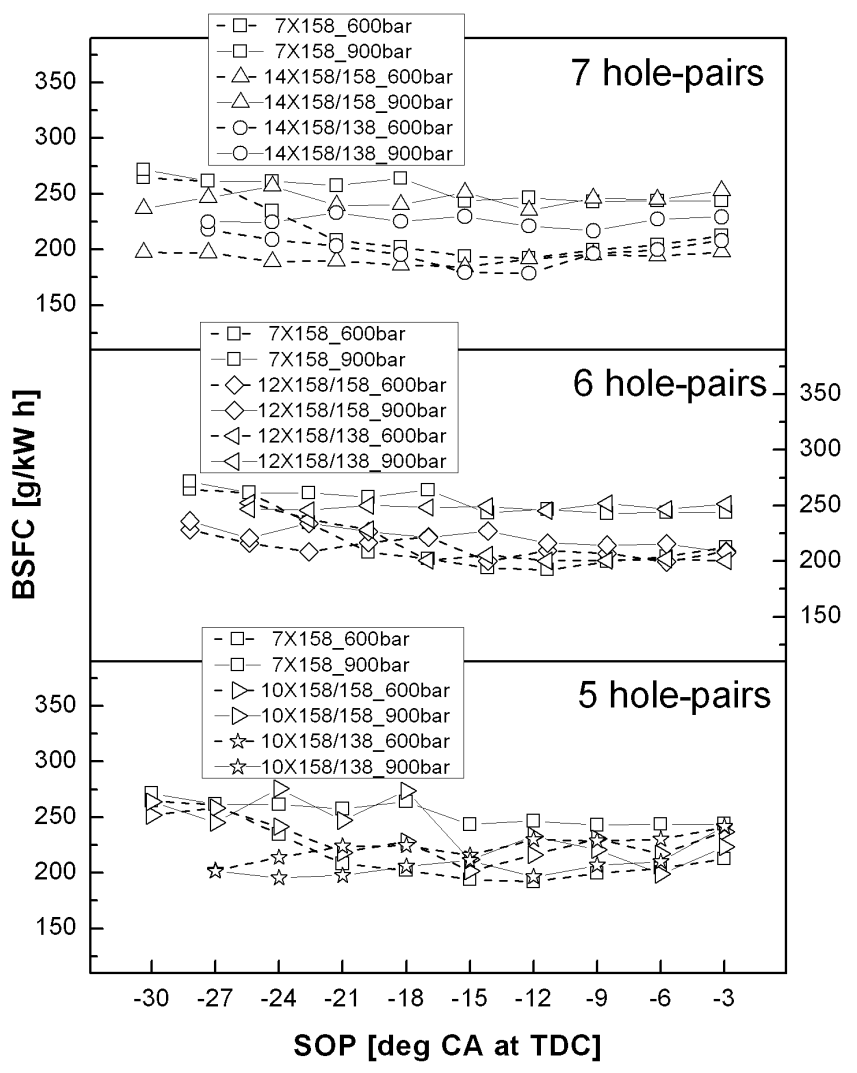

Fig. 11 Brake specific fuel consumption (b.s.f.c.) for TP1: $1400 \mathrm{r} / \mathrm{min}, 600$ and 900 bar rail pressure, 4.5 bar i.m.e.p., $4 \mathrm{~g} / \mathrm{kg}$ fuel of $\mathrm{NO}_{x}$ 


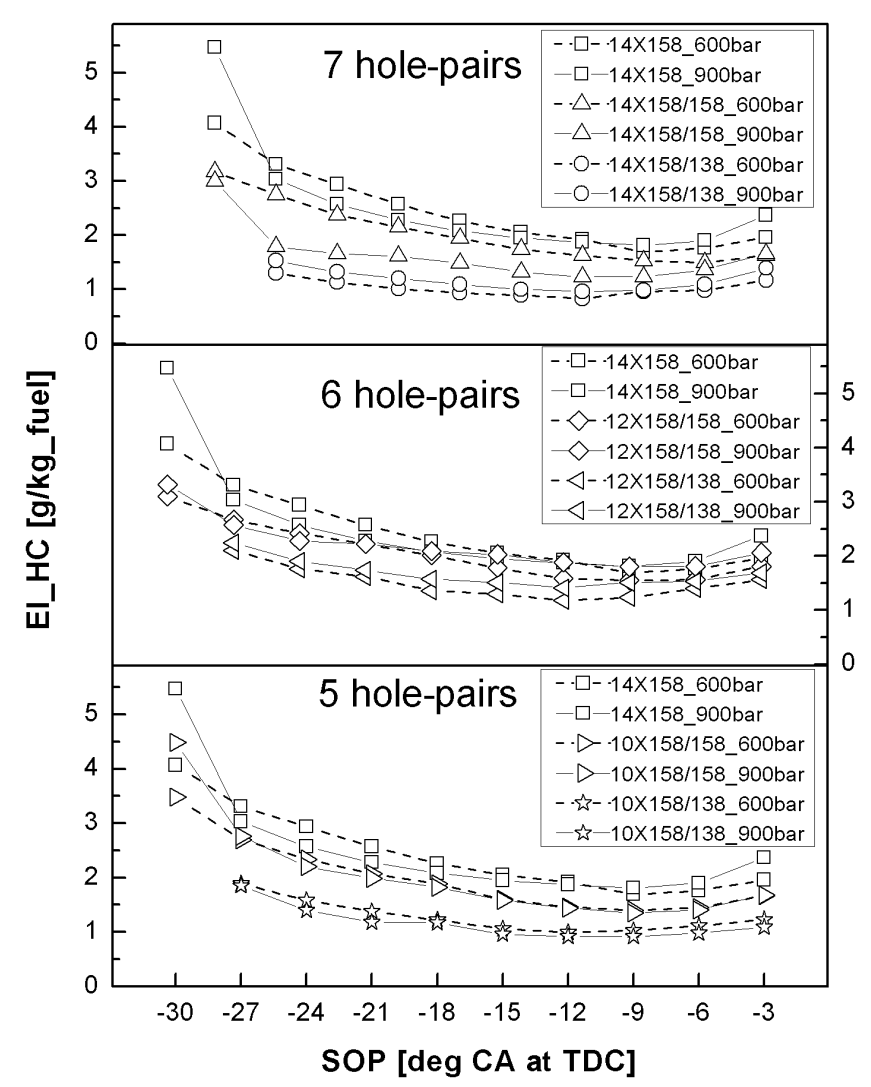

Fig. 12 HC emissions for TP1: $1400 \mathrm{r} / \mathrm{min}, 600$ and 900 bar rail pressure, 4.5 bar i.m.e.p., $4 \mathrm{~g} / \mathrm{kg}$ fuel of $\mathrm{NO}_{x}$

top and combustion chamber walls owing to higher dilution and long ignition delays. At late injection timings, combustion occurs past TDC when the expansion has already begun and the temperature starts to fall. More fuel close to the chamber walls and a lower temperature of combustion are both contributors to higher HC emissions. The reference nozzle with a long spray tip penetration and larger orifices shows higher HC than the cluster nozzles. The vertical clusters have relatively lower HC than the horizontal clusters. This is perhaps due to the fact that the horizontal clusters inject more fuel towards the top part of the piston than the vertical clusters because of the vertical clusters having two spray cones with one of them narrower than the spray cone for the horizontal clusters. It may also be helped by the fact that a spray with a slightly narrower spray-cone angle takes a little longer to touch the piston wall in a re-entrant-type combustion chamber than a spray with a conventional spray-cone angle. There is no common trend for change in injection pressure, but HC emissions are worse with high-pressure injection in most cases. The injection pressure has to be limited to keep HC emissions and the fuel consumption at acceptable levels under part-load condition.

Figure 13 shows smoke emissions of five-, six-, and seven-hole-pair clusters with different rail pressures for a variation in SOP. All the results are for TP1 with an $\mathrm{NO}_{x}$ emission index of 4 . For the clusters, the smoke emission is lower than for the reference nozzle under early injection timings, but it becomes much higher than for the reference nozzle under conventional injection timing for TP1. The sprays from the clusters have a shorter spray tip penetration and cannot entrain more air than the reference nozzle with shorter ignition delay as in the case of conventional timings. However, the clusters show improved smoke emissions with higher injection pressure. With increase in injection pressure, the clusters show a potential to reduce, to some extent, the adverse effects on spatial distribution of spray caused by better atomization. For 600 bar rail pressure, the horizontal clusters have higher smoke than the vertical clusters at conventional injection timings. The horizontal clusters make rich zones in the chamber because the ignition delays for the conventional injection timings with relatively higher temperature and pressure are shorter than the

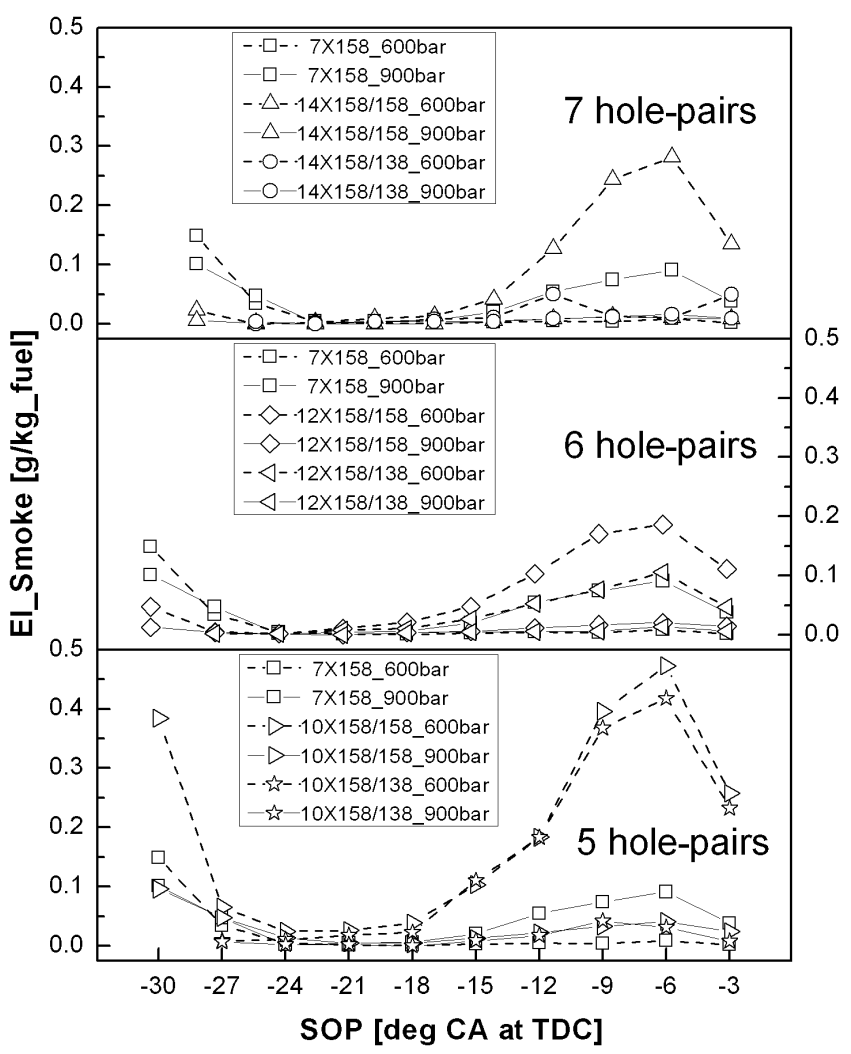

Fig. 13 Smoke emissions for TP1: $1400 \mathrm{r} / \mathrm{min}, 600$ and 900 bar rail pressure, 4.5 bar i.m.e.p., $4 \mathrm{~g} / \mathrm{kg}$ fuel of $\mathrm{NO}_{x}$ 
ignition delay for early and late injection timings, and the distances between the tip of the sprays from adjacent hole groups in the horizontal configuration are also very small for short spray penetrations. Cluster $10 \times 158 / 138$, which was designed with smaller orifices, also shows high smoke levels. It had a lower flow number and required longer injection duration than the other clusters to inject a similar amount of fuel to maintain constant i.m.e.p. There is also an interesting result for the reference nozzle. The reference nozzle with 900 bar injection pressure shows higher smoke than with 600 bar injection pressure for conventional injection timings. The increase in spray tip penetration with higher injection pressure makes a richer mixture near the piston walls for the reference nozzle. However, the horizontal clusters and a vertical cluster (cluster $10 \times 158 / 138$ ) showed substantial improvement in smoke emissions for higher injection pressure. It seems that, unlike the reference nozzle, their spray tip penetration is inadequate for 600 bar and is improved for 900 bar. For high injection pressure, the clusters show lower smoke than the reference nozzle for TP1.

\subsubsection{High load condition (TP2)}

Clusters were also used to investigate the effects of rail pressure for different SOP under high-load condition, and the results were compared with the reference nozzle. The injection timing under high load is limited by intense diesel knock. For this reason, the injection timings were varied between $-10^{\circ} \mathrm{CA}$ at TDC and $4^{\circ} \mathrm{CA}$ at TDC. It is necessary to find a solution for the problem with high smoke levels under high-load condition. With the use of smaller-orifice nozzles, less fuel adheres to the wall because the distance reached by the fuel spray is shortened. This is considered to be caused by a low penetrating force due to smaller droplet sizes in the spray, and by an evaporation-prone characteristic due to a larger ratio of surface area to droplet weight. Only the smoke emissions are compared, because the $\mathrm{HC}$ and $\mathrm{CO}$ are not of major concern in this condition. Moreover, the performance of all the nozzles with respect to $\mathrm{HC}$ and $\mathrm{CO}$ was quite similar. The size of the orifices, spray targeting, and spray tip penetration should be the important parameters for TP2, because a great deal of fuel was injected in this condition while the engine speed was relatively low, and the spray tip penetrations were high enough to see the effect of spray targeting. The closely placed orifices help to hold the momentum, maintaining the penetration of the spray. The clusters were investigated in a conventional wide piston bowl.

The results of b.s.f.c. using five-, six-, and sevenhole-pair clusters are shown for variation in SOP in Fig. 14. The clusters, except cluster $10 \times 158 / 138$, have better fuel consumption than the reference nozzle in all injection timings for TP2. Cluster $10 \times 158 / 138$ with a lower flow number requires longer injection timing than the other clusters, and the combustion period is lengthened. However, the cluster with high pressure improves the fuel consumption.

The results of smoke emissions for five-, six-, and seven-hole-pair clusters are shown in Fig. 15. The vertical clusters have relatively higher smoke emissions than the horizontal clusters and the reference nozzle. The horizontal clusters, which were designed with a $158^{\circ}$ spray cone angle, the same as the reference nozzle, have better spray targeting and mixture formation near the piston bowl. The spray of horizontal clusters is injected towards the top part of the piston bowl, from where it is guided along the bowl surface towards the centre of the bowl. In this way, sufficient air can be entrained during the mixing and combustion process, and thus the burning rate is accelerated. However, the results of

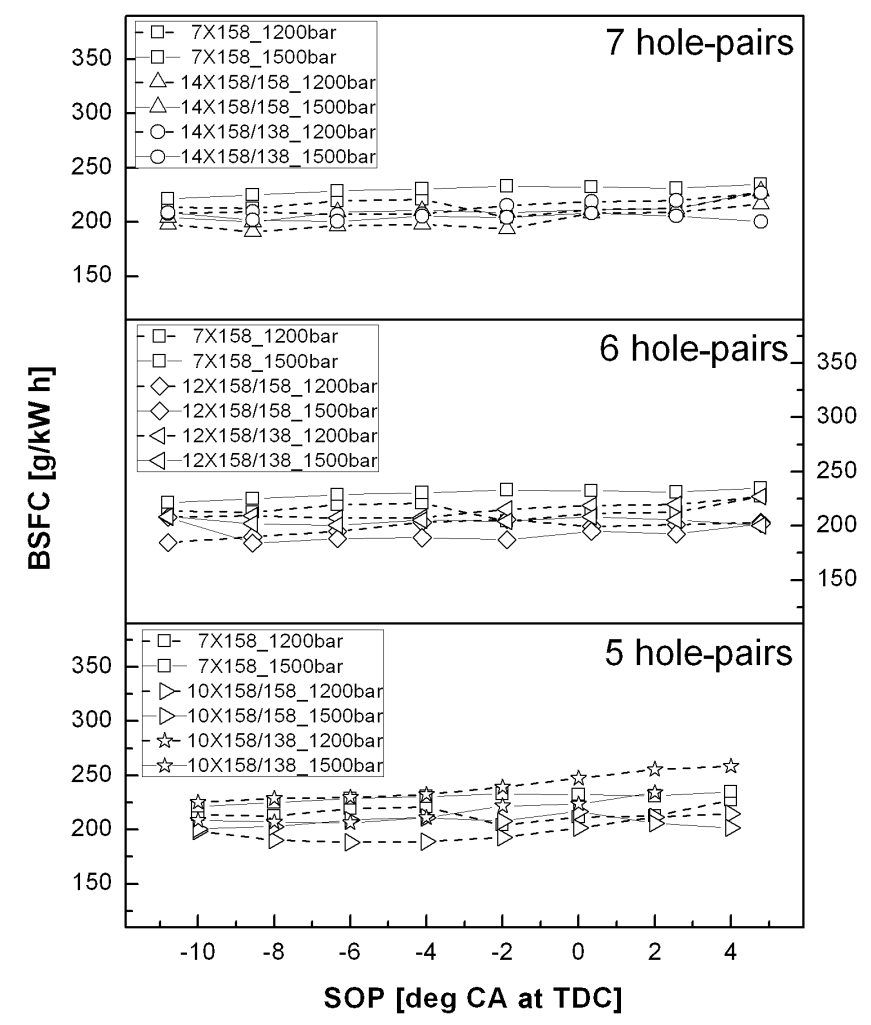

Fig. 14 Brake specific fuel consumption (b.s.f.c.) for TP2: $1400 \mathrm{r} / \mathrm{min}, 1200$ and 1500 bar rail pressure, 10.5 bar i.m.e.p., $4.5 \mathrm{~g} / \mathrm{kg}$ fuel of $\mathrm{NO}_{x}$ 


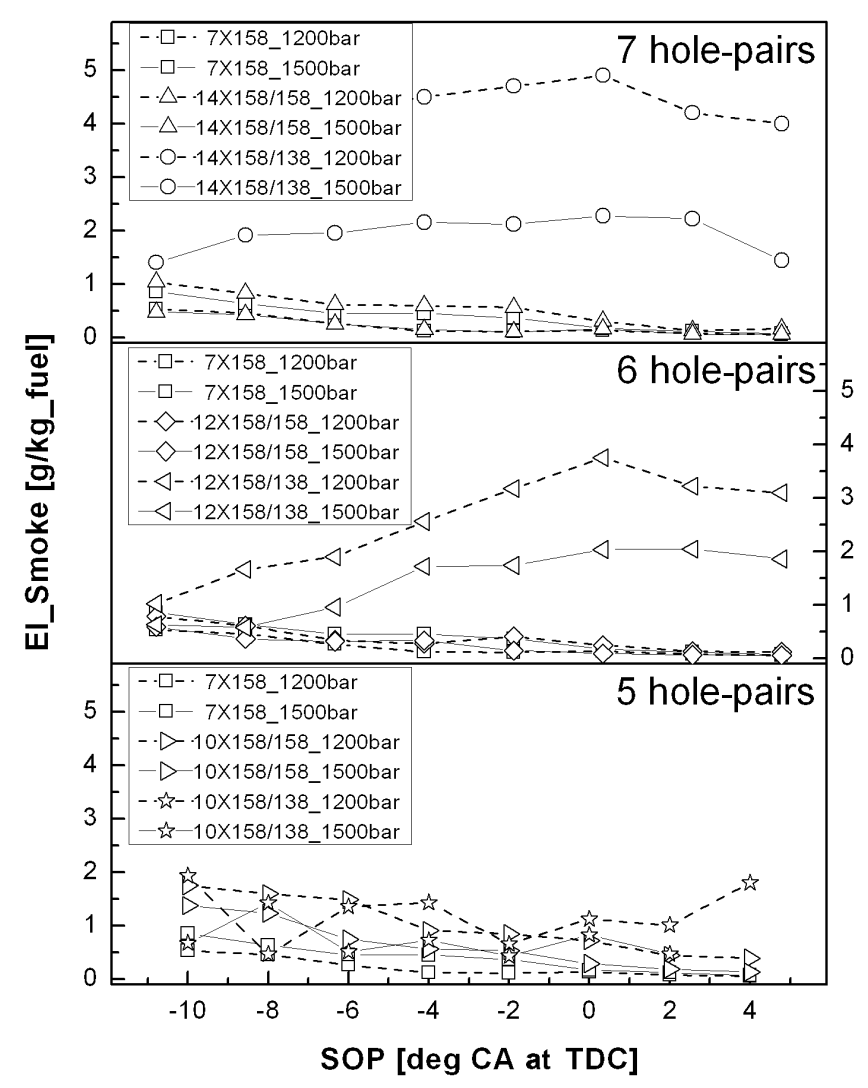

Fig. 15 Smoke emissions for TP2: $1400 \mathrm{r} / \mathrm{min}, 1200$ and 1500 bar rail pressure, 10.5 bar i.m.e.p., $4.5 \mathrm{~g} / \mathrm{kg}$ fuel of $\mathrm{NO}_{x}$

horizontal clusters do not show significantly lower soot levels compared with the reference nozzle. The clusters with small orifices improve the fuel atomization and evaporation, but, because of the shorter penetrations compared with the reference nozzles, their sprays lose momentum faster when used in a wide piston bowl. A combination of clusters with small orifices and high-pressure injection can achieve lean combustion with the development of faster wall jets producing more turbulence and better mixing. As the spray reaches the piston walls, the vapour spreads over a larger surface area and moves further along the wall towards the bottom of the bowl and radially inwards to the centre of the bowl. This improves the mixing of the fuel with the bulk of the air in the bowl. The horizontal clusters with high-pressure injection show lower smoke than the vertical clusters and the reference nozzle. The vertical clusters show higher smoke. It seems that the two sprays, one directed towards the top part of the bowl and the other towards the middle or the bottom part of the bowl, guided against each other by the bowl contour, merge with each other and make a rich zone near the piston wall. This might be a source of higher smoke emissions for the vertical clusters.

\section{CONCLUSIONS}

Six clusters were investigated with different rail pressures for two different test points, and the results were compared with a reference nozzle. The test points were denoted as TP1 for low-load condition and TP2 for high-load condition.

1. Ignition delay in the case of the cluster nozzles is generally shorter than in the case of the conventional nozzle under TP1. The rate of heat release is also higher for the cluster nozzles. The combustion period is shortened. This effect is further enhanced with increase in rail pressure.

2. The clusters have ignition delays similar to that of the reference nozzle under TP2, but the heat release rates of the clusters are higher than for the reference nozzle during premixed combustion. A lower rate of heat release for the clusters than for the reference nozzle during the mixing-controlled combustion phase indicates that a large number of the droplets already get consumed during the premixed combustion phase for the clusters.

3. Under conventional injection timing for TP1, the seven-hole-pair clusters show lower smoke than the other clusters, but higher smoke than the reference nozzle for a lower rail pressure. With a higher rail pressure, the smoke emissions of all the clusters are brought down to levels comparable with those of the reference nozzle.

4. The clusters improve HC, smoke, and fuel consumption in PCCI condition. Clusters with smaller orifices show better results for smoke in the lean mixture conditions present in PCCI.

5. The smoke emissions of clusters were also reduced by increasing the rail pressure under TP2. The horizontal clusters with high-pressure injection show lower smoke than the reference nozzle, but the vertical clusters have higher smoke than the reference nozzle.

A combination of high pressure injection and cluster nozzles is one of the alternative hardware configurations to achieve lean combustion. In spite of the experiments being performed with a wide piston bowl without an optimized swirl level, some clusters with high injection pressure have a lower smoke level than the reference nozzle at all test points. However, the investigation did not address the effects of jet-wall or jet-jet interactions, which 
occur in engines, or the effects of swirl. To make the use of clusters in a diesel engine feasible, a significant redesign of the typical in-cylinder geometry would probably be required to promote efficient air utilization.

\section{ACKNOWLEDGEMENTS}

This work was supported financially by General Motors R\&D. The authors would like to thank the working group of the GM Collaborative Research Lab at RWTH Aachen University for their support and contribution.

\section{REFERENCES}

1 Nakakita, K., Miwa, K., Ohsawa, K., Takahashi, T., Watanabe, S., and Sami, H. Effects of high pressure fuel injection on the combustion and exhaust emission of a high-speed DI diesel engine. JSAE Rev., 1991, 12(1).

2 Yokata, H., Kamimoto, T., Kosaka, H., and Tsujimura, K. Fast burning and reduced soot formation via ultra-high pressure diesel fuel injection. SAE paper 910225, 1991.

3 Su, T. F., Chang, C. T., Reitz, R. D., Farrell, P. V., Pierpont, A. D., and Tow, T. C. Effect of injection pressure and nozzle geometry on spray SMD and D.I. emissions. SAE paper 952360, 1995.

4 Varde, K. S. and Watanabe, T. Characteristics of high pressure spray and exhaust emissions in a single cylinder DI diesel engine. SAE paper 200005-0333, 2000.

5 Henein, N. A., Bhattacharyya, A., Schipper, J., and Kastury, A. Effect of injection pressure and swirl motion on diesel engine-out emission in conventional and advanced combustion regimes. SAE paper 2006-01-0076, 2006.

6 Ishikawa, N. and Niimura, K. Analysis of diesel spray structure using magnified photography and PIV. SAE paper 960770, 1996.

7 Han, J. S., Lu, P. H., Xie, S. B., Lai, M. C., and Henein, N. A. Investigation of diesel spray primary break-up and development for different nozzle geometries. SAE paper 2002-01-2775, 2002.
8 Hiroyasu, H., Arai, M., and Tabati, M. Empirical equations for the Sauter mean diameter of a diesel spray. SAE paper 890464, 1989.

9 Stanton, W. S. and Rutland, C. J. Modeling fuel film formation and wall interaction in diesel engines. SAE paper 960628, 1996.

10 Dec, J. E. A conceptual model of D.I. diesel combustion based on laser sheet imaging. SAE paper 970873, 1997.

11 Siebers, D. L. and Higgins, B. S. Effects of injector conditions on the flame lift-off length of DI diesel sprays. Sandia report SAND2000-8249, 2000.

12 Sjoeberg, M. Correlation between flame pattern, heat-release and emissions for a DI diesel engine with rotating injector and variable swirl. SAE paper 2001-01-2003, 2001.

13 Hottenbach, P., Gruenefeld, G., and Brands, T. An experimental investigation of combustion and soot formation of sprays from cluster nozzles for D.I. diesel engines. SAE paper 2009-01-0855, 2009.

14 Won, H. W., Sharma, A., Hottenbach, P., Gauding, M., Robert, F. X., Peters, N., Gruenefeld, G., Durrett, R., Plazas, A., and Singh, S. Investigation of particulate emissions for cluster-nozzle concepts in DI diesel engines. In Proceedings of ICLASS2009, 2009, ICLASS2009-148.

15 Won, H. W., Sharma, A., Moon, S. E., Vanegas, A., and Peters, N. An experimental study of cluster nozzles for DI diesel engine. SAE paper (submitted March 2009), 2009.

16 Pawlowski, A., Kneer, R., Lippert, A. M., and Parrish, S. E. Investigation of the interaction of sprays from clustered orifices under ambient conditions relevant for diesel engines. SAE paper SAE 2008-01-0928, 2008.

17 Cardenas, M., Hottenbach, P., Kneer, R., and Gruenefeld, G. Investigations of clustered diesel jets under quiescent high-pressure and hightemperature conditions using Mie, Schlieren and chemiluminescence imaging. SAE paper (submitted May 2009), 2009.

18 Dodd, A. and Holubecki, Z., The measurement of diesel exhaust smoke, MIRA report 1965/10, 1965.

19 Gao, J., Matsumoto, Y., and Nishida, K. Effects of group-hole nozzle specifications on fuel atomization and evaporation of direct injection diesel spray. SAE paper 2007-01-1889, 2007. 